\title{
Human Epididymis Protein 4 (HE4) Reference Limits in Polish Population of Healthy Women, Pregnant Women, and Women with Benign Ovarian Tumors
}

\author{
Emilia Gasiorowska ${ }^{D},{ }^{1}$ Tomasz Kluz, ${ }^{2}$ Dawid Lipski, ${ }^{3}$ Wojciech Warchol, ${ }^{4}$ \\ Andrzej Tykarski, ${ }^{3}$ and Ewa Nowak-Markwitz ${ }^{1}$ \\ ${ }^{1}$ Department of Gynecology, Obstetrics and Gynecologic Oncology, Division of Gynecologic Oncology, \\ Poznan University of Medical Sciences, Poland \\ ${ }^{2}$ Department of Obstetrics and Gynecology, Fryderyk Chopin University Hospital No 1, Rzeszów University, Poland \\ ${ }^{3}$ Department of Hypertensiology, Angiology and Internal Medicine, Poznan University of Medical Sciences, Poland \\ ${ }^{4}$ Department of Biophysics, Poznan University of Medical Sciences, Poland
}

Correspondence should be addressed to Emilia Gasiorowska; emilia.gasiorowska@gmail.com

Received 9 February 2019; Revised 14 May 2019; Accepted 16 July 2019; Published 22 August 2019

Academic Editor: Sunil Hwang

Copyright (c) 2019 Emilia Gasiorowska et al. This is an open access article distributed under the Creative Commons Attribution License, which permits unrestricted use, distribution, and reproduction in any medium, provided the original work is properly cited.

\begin{abstract}
Objectives. Defining precisely the normal range of HE4 protein is crucial for the proper interpretation of tumor marker results and for a more efficient diagnosis of ovarian malignancy. The aim of our study was to evaluate a reference limit of HE4 protein in a population to promote and facilitate the common use of HE4 protein assays. We also tried to identify potential association of HE4 levels with other conditions such as smoking, age, BMI, and creatinine levels. Methods. Blood samples were collected from 617 patients divided into three groups: healthy, pregnant, and with benign ovarian tumors. Serum HE4 concentrations were measured following a standard procedure. HE4 reference ranges for each group and association of HE4 levels with BMI, creatinine, and smoking were investigated. Results. HE4 reference limit for healthy patients equals $85 \mathrm{pmol} / \mathrm{l}$, which becomes $73 \mathrm{pmol} / \mathrm{l}$ and $93 \mathrm{pmol} / \mathrm{l}$ for pre and postmenopausal subgroups, respectively. There is a statistically significant correlation between HE4 serum level and smoking $(p=0.000001)$ and there is no correlation with creatinine. But if we take into account age and smoking, in multivariate analysis, there is a correlation. For pregnant, the upper limit values of normal HE4 levels are $55 \mathrm{pmol} / \mathrm{l}$ (median $=40 \mathrm{pmol} / \mathrm{l}), 80 \mathrm{pmol} / \mathrm{l}($ median $=43 \mathrm{pmol} / \mathrm{l})$, and $106 \mathrm{pmol} / \mathrm{l}($ median $=53 \mathrm{pmol} / \mathrm{l})$ for the first, second, and third trimesters, respectively. Conclusions. HE4 protein value strongly depends on the patient's age and smoking. The serum concentration of HE4 marker increases with the duration of pregnancy. Understanding the normal range of HE4 protein enables the correct interpretation of marker measurements. This may result in an earlier and more effective diagnosis of ovarian cancer.
\end{abstract}

\section{Introduction}

Human epididymis protein 4 (HE4) is a glycoprotein originally found in the epithelial cells of the human epididymis. It belongs to the family of serine protease inhibitors (WAP domain proteins) and plays a role in carcinogenesis, tumor progression, and metastasis $[1,2]$. Since 2011, the HE4 protein has become an integral diagnostic tool for ovarian cancer [1]. Its levels, which are a malignancy risk predictor in women with adnexal mass, are measured in single tests, in series of tests, or as part of a Risk of Ovarian Malignancy Algorithm (ROMA) [2]. It is necessary to know how to interpret single and serial measurements of HE4 protein concentration. However, studies to date have not provided a universal reference range of HE4 levels for healthy women from different populations. HE4 norms used by different laboratories vary, and it is advisable to establish consistent norms for specific populations. The norm for premenopausal 
TABLE 1: Study group characteristics.

\begin{tabular}{|c|c|c|c|c|c|c|}
\hline \multirow{2}{*}{ Group } & \multicolumn{2}{|r|}{ All } & \multicolumn{2}{|r|}{ Premenopausal } & \multicolumn{2}{|r|}{ Postmenopausal } \\
\hline & Total of patients $(n)$ & Median age (range) (years) & $n$ & Median age (range) (years) & $n$ & Median age (range) (years) \\
\hline Healthy women & 265 & $48(17-78)$ & 157 & $38(17-54)$ & 108 & $59(45-78)$ \\
\hline $\begin{array}{l}\text { Women with a } \\
\text { benign tumor }\end{array}$ & 195 & $43(16-83)$ & 139 & $37(16-53)$ & 56 & $60(49-83)$ \\
\hline Pregnant women & 157 & $30(18-46)$ & & & - & \\
\hline
\end{tabular}

women of $<70 \mathrm{pmol} / \mathrm{l}$ and for postmenopausal women of $<140 \mathrm{pmol} / \mathrm{l}$ is the most commonly defined. Precisely defining the normal range is crucial for proper interpretation of tumor marker results and for a more efficient diagnosis of ovarian malignancy. Moreover, defining the normal range of HE4 levels in pregnant women would be even more useful because the cases of pregnancy with adnexal masses represent one of the most important obstetric clinical issues that leads to additional hospitalizations for pregnant women. Knowing a reference limit would bring both medical and economic benefits, as the eventual maternal and fetal complications, and the financial costs, of unnecessary surgical interventions could be avoided.

In order to promote and facilitate the use of HE4 protein assays, we attempted to define a normal range of HE4 protein in Polish populations of healthy women, pregnant women, and women with benign ovarian tumors. We also attempted to identify any potential associations between HE4 levels and parameters such as smoking, age, BMI, and creatinine levels.

\section{Materials and Methods}

We defined the inclusion criteria for our study based on the criteria in the literature that documents the associations between the HE4 marker and neoplasms of the female reproductive tract [1], the breasts [3], the pancreas [4], and the respiratory system [5]. And we also considered associations with chronic kidney disease [6] and any other conditions that are known to influence HE4 levels. Our inclusion criteria were as follows: absence of pathological changes in the reproductive organs confirmed by gynecological and ultrasound examinations; no history of chronic or acute infection in the past 6 months confirmed by CRP $<5$; no history of blood transfusion or surgical treatment in the past 6 months; creatinine level $<1 \mathrm{mg} / \mathrm{dl}$; and no history of acute or chronic diseases of the kidney, liver, or respiratory system.

A total of 617 patients participated in the study. The Local Bioethics Committee approved the study (reference number 838/14), and informed consent was obtained from all patients participating in the study.

Our study population was divided into three groups, and serum samples were collected from each participant. Blood samples were obtained by venous puncture, centrifuged, and stored at $-80^{\circ} \mathrm{C}$ until the analyses were performed. The $\mathrm{HE} 4$ assays were performed with the use of electrochemiluminescence Elecsys ${ }^{\circledR}$ ECLIA by ROCHE. The concentrations were analyzed by the COBAS apparatus, used according to the manufacturer's instructions.
The first of our groups was comprised of patients admitted to the Gynecologic Oncology Department of Poznan University of Medical Sciences for surgical treatment of pelvic organ prolapse and urinary incontinence, in addition to the patients attending the Department of Hypertensiology, Angiology, and Internal Medicine of Poznan University of Medical Sciences for prophylactic checkups. The second group was comprised of patients of the Gynecologic Oncology Department of Poznan University of Medical Sciences who had qualified for surgical treatment of benign ovarian tumors followed by histopathological diagnosis. The third group was comprised of pregnant women attending routine control examinations at the Department of Obstetrics and Gynecology of Rzeszów University.

Patients with benign ovarian tumors were included in the study because the HE4 protein is registered in the differential diagnosis of the women's ovarian tumors, and not as part of a screening test in healthy patients. Therefore, it was very important to determine the HE4 limit value not only for healthy patients but also for patients with benign tumors, to help differentiate those patients from ovarian cancer patients.

The first group comprised of 265 healthy women aged 17 to 78 who exhibited no changes in the adnexa. We subdivided this first group into pre $(n=157)$ and postmenopausal groups $(n=108)$, with median ages of 38 years (range 17-54) and 59 years (range 45-78), respectively (Table 1).

The second group comprised of 195 patients with a benign ovarian tumor diagnosed by histopathological examination, of which 139 patients were premenopausal (median age 37 , range 16-53) and 56 patients were postmenopausal (median age 60, range 49-83). Patients diagnosed with ovarian cancer intraoperatively were not included in the study.

The third group comprised of 157 healthy women with a median age of 30 (range 18-46), with a single pregnancy and with no concomitant diseases. This group was subdivided into trimesters, with 57 women in the first trimester, 24 in the second, and 76 in the third (Table 1).

After serum HE4 concentrations were assayed, we analyzed the levels considering patient age and classified the findings by age decades.

We established a 95\% confidence interval for the normal range of $\mathrm{HE} 4$ with a $95 \%$ confidence limit (CL95\%). This way we developed a separate reference range for each group, namely, for the pre and postmenopausal groups, as well as for the healthy group, and again separately for the healthy group that included the benign tumor patients.

We also analysed the data for any association between HE4 levels and the patients' BMI, creatinine, and smoking. 
TABLE 2: HE4 in healthy patients and in those with an ovarian benign tumor by age decades.

\begin{tabular}{|c|c|c|c|c|c|}
\hline \multirow[b]{2}{*}{ Age category (years) } & \multirow[b]{2}{*}{ Number of patients } & \multicolumn{2}{|c|}{ Patients free of adnexal changes } & \multicolumn{2}{|c|}{ Patients with benign adnexal changes } \\
\hline & & Median (pmol/l) & $\begin{array}{l}\text { Range (min-max }) \\
(\mathrm{pmol} / \mathrm{l})\end{array}$ & Median (pmol/l) & $\begin{array}{c}\text { Range (min-max }) \\
(\mathrm{pmol} / \mathrm{l})\end{array}$ \\
\hline $16-19$ & 11 & 42.0 & $43-60$ & 48 & $34-67$ \\
\hline $20-29$ & 75 & 40.5 & $15-61$ & 52.0 & $33-94$ \\
\hline $30-39$ & 80 & 45.0 & $32-79$ & 54.0 & $31-212$ \\
\hline $40-49$ & 107 & 48.0 & $24-92$ & 53.0 & $25-95$ \\
\hline $50-59$ & 107 & 51.0 & $24-118$ & 58.0 & $41-101$ \\
\hline $60-69$ & 63 & 52.0 & $40-120$ & 67.0 & $33-120$ \\
\hline 70-79 & 15 & 62.0 & $48-188$ & 96.5 & $44-209$ \\
\hline $80-83$ & 2 & - & - & 119.5 & $98-141$ \\
\hline
\end{tabular}

TABLE 3: Reference range of HE4 for healthy patients and for the extended group that includes those with benign adnexal changes.

\begin{tabular}{lcccc}
\hline Studied group & Menopausal status & Median (pmol/l) & Number of patients & HE4 norm (pmol/l) (CL95\%) \\
\hline Healthy women & All & 48 & 265 & $33-85$ \\
Healthy women & Pre & 44 & 157 & $15-73$ \\
Healthy women & Post & 53 & 108 & $38-93$ \\
Healthy+benign conditions & All & 49.5 & 460 & $33-91.5$ \\
Healthy+benign conditions & Pre & 40 & 296 & $32-79$ \\
Healthy+benign conditions & Post & 55 & 164 & $40-117$ \\
Patients with endometrial cysts & All & 52 & 72 & $35-83$ \\
Patients with cystadenomas & All & 52 & 51 & $34-119$ \\
Patients with dermoid cysts & All & 53 & 39 & $33-94$ \\
Patients with serous cysts & All & 51 & 33 & $37-79$ \\
\hline
\end{tabular}

The HE4 levels per trimester of pregnancy were analyzed, and a reference range was defined for each trimester.

The statistical analysis for our study was performed by the Biophysics Department at the Poznan University of Medical Sciences using Statistica 10 software from StatSoft; and $p<0.05$ indicated a statistically significant difference. The Shapiro-Wilk test, the Spearman's test, the Kruskal-Wallis test, and the Mann-Whitney test were used.

\section{Results}

We observed that the HE4 levels rose correspondingly with the rising age of patients for both the healthy and the benign tumor groups (Table 2).

HE4 median and range were established as reference norms for each group. The $95 \%$ cutoff value for the healthy patients was $85 \mathrm{pmol} / \mathrm{l}$, and for the pre and postmenopausal subgroups, it was $73 \mathrm{pmol} / \mathrm{l}$ and $93 \mathrm{pmol} / \mathrm{l}$, respectively. After extending the healthy group to include the benign adnexal mass group, the new HE4 limit value was $91.5 \mathrm{pmol} / \mathrm{l}$, and correspondingly, for the pre and postmenopausal women, it was $79 \mathrm{pmol} / \mathrm{l}$ and $117 \mathrm{pmol} / \mathrm{l}$, respectively (Table 3 ).

The mean BMI was $25 \mathrm{~kg} / \mathrm{m}^{2}$ (range $17-43 \mathrm{~kg} / \mathrm{m}^{2}$ ). The average creatinine concentration was $0.73 \mathrm{mg} / \mathrm{dl}$ (range $0.34-1.08 \mathrm{mg} / \mathrm{dl}$ ). $27 \%$ of the patients smoked and $73 \%$ did not smoke. Among the members of the premenopausal group, 36\% women smoked and that of the postmenopausal
TABle 4: Association of HE4 levels with BMI, creatinine, and smoking for the healthy and the benign tumor group.

\begin{tabular}{lcc}
\hline & $p$ & Spearman's $r$ \\
\hline HE4 \& BMI & 0.294 & 0.081 \\
HE4 \& creatinine & 0.997 & 0.001 \\
HE4 \& smoking & 0.001 & 0.375 \\
\hline
\end{tabular}

group, $17 \%$ smoked. When we analyzed the associations between the HE4 concentrations and the women's BMI, creatinine, and smoking, we found no correlation for BMI or creatinine. However, we did find a positive correlation between HE4 levels and smoking $(p=0.001)$, which is presented in Table 4 and Figure 1. Although, there is no statistically significant relationship between HE4 and creatinine, multivariate analysis reveals a statistically significant relationship between them, if we take into account age and smoking (Table 5).

The median HE4 concentration of the pregnant women was $46.0 \mathrm{pmol} / \mathrm{l}$ (range $15-117 \mathrm{pmol} / \mathrm{l}$ ). After adjusting for the gestation age, we established that the HE4 confidence limits were $55 \mathrm{pmol} / \mathrm{l}$ (median $40 \mathrm{pmol} / \mathrm{l}$ ), $80 \mathrm{pmol} / \mathrm{l}$ (median $43 \mathrm{pmol} / \mathrm{l}$ ), and $106 \mathrm{pmol} / \mathrm{l}$ (median $53 \mathrm{pmol} / \mathrm{l}$ ) for the first, second, and third trimesters, respectively (Table 6).

The differences in HE4 concentrations were statistically significant when separately comparing the results for the first 


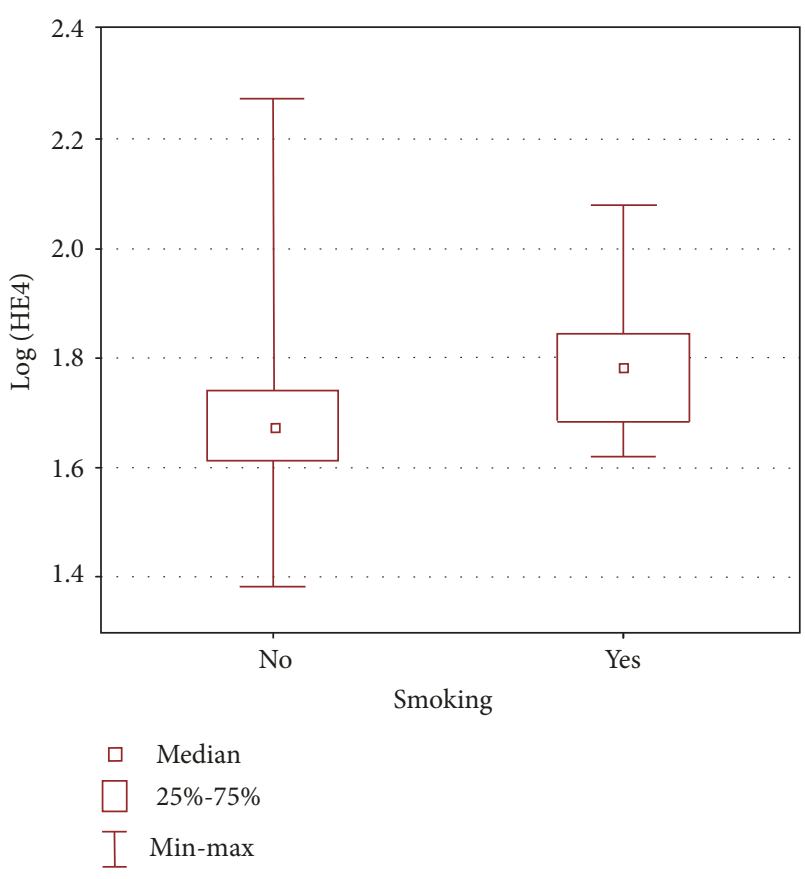

FIGURE 1: Range of HE4 concentrations in smokers and nonsmokers.

and second trimesters with those of the third trimester (I and III, II and III) (Figure 2).

Despite the absence of any statistically significant difference between the first and second trimester results, analysis clearly showed that as pregnancy progresses, so does the concentration of the HE4 protein.

\section{Discussion}

4.1. HE4 and AGE. It is very important for clinical practitioners to have a clear and universal reference range for the HE4 protein at their disposal and to be aware of the factors that may influence its concentration levels.

The correlation we observed between rising HE4 concentration and advancing age has particular, and cautionary, implications when making clinical decisions based on HE4 levels in a patient when these levels are monitored over the course of many years.

Our study's findings, which are in line with those of the literature [7], show that the range of possible differences in HE4 levels that correspond with rising age is of particular importance for clinicians. For instance, when comparing the HE4 levels of women patients at different ages using 20 years old as the baseline, the levels were $9 \%$ higher by the age of 40 and $63 \%$ higher by the age of 70 .

Moore et al. report a median HE4 level of $43.5 \mathrm{pmol} / 1$ for 40 -year-olds and $66.9 \mathrm{pmol} / 1$ for 70 -year-old women patients [8]. Our study showed the comparable results of $48 \mathrm{pmol} / \mathrm{l}$ and $62 \mathrm{pmol} / \mathrm{l}$ for women at age 40 years and 70 years, respectively.

Such findings point to potential problems with interpretation of HE4 assays, particularly when different results arise from examinations carried out over several years, such as in cases of monitoring of at-risk patients whose rising HE4 concentration may be attributed to their advancing age alone, irrespectively of any potential malignancy. For this reason, we postulate that doctors should know the positive correlations of HE4 protein levels with age, as well as the reference values for each age group.

Studies report varying reference ranges for HE4 as a consequence of the differences between the various study populations. However, overall, those studies' results are comparable. Moore et al. found the HE4 reference limit for pre and postmenopausal American women to be $89 \mathrm{pmol} / \mathrm{l}$ and $128 \mathrm{pmol} / \mathrm{l}$, respectively [8]. In turn, our study, based on a Central European population, and the same groupings, found the reference limits to be $73 \mathrm{pmol} / \mathrm{l}$ and $93 \mathrm{pmol} / \mathrm{l}$, respectively. Interestingly, when we include women with benign adnexal changes who are otherwise healthy, our reference limits became closer to Moore's American findings and became $89 \mathrm{pmol} / \mathrm{l}$ and $117 \mathrm{pmol} / \mathrm{l}$, respectively.

Another study, published in 2015, attempted to define HE4 reference ranges within a Chinese study population and found the norm to be between $29.30 \mathrm{pmol} / \mathrm{l}$ and $68.79 \mathrm{pmol} / \mathrm{l}$ for premenopausal women and between $35.96 \mathrm{pmol} / \mathrm{l}$ and $114.43 \mathrm{pmol} / \mathrm{l}$ for postmenopausal women [9].

In contrast, Molina et al. defined the reference range for groups of pre and postmenopausal healthy women based on a total study population of 66 patients, as $132 \mathrm{pmol} / \mathrm{l}$ and $138 \mathrm{pmol} / \mathrm{l}$, respectively [10]. Despite these evident associations between HE4 levels and age, diagnostic tests that involve the HE4 marker and that discriminate for menopausal status or age do not vary in either their sensitivity or specificity in the detection of ovarian cancer. In the study of Karlsen et al. that comparing RMI (Risk of Malignancy Index), ROMA, and CPH-I (Copenhagen Index, with inputs of CA125, HE4, and age), the authors found that at a sensitivity set of $75 \%$, specificity scored $93.3 \%, 93.8 \%$, and $93.2 \%$ for each test, respectively; and they concluded from this that none of the three methods is superior to any of the others [11].

4.2. HE4 and BMI. Our study found no association between HE4 levels and the patients' BMI. However, Bolstad et al. reported that, when comparing $\mathrm{HE} 4$ concentrations for $\mathrm{BMI}=20$, there was a $5 \%$ decrease in the levels with a BMI of $=25$ and a $10 \%$ decrease with a BMI of $=30$ [7]. The significance of this finding remains unknown.

4.3. HE4 and Smoking and Other Conditions. Apart from age, our study points to another factor that correlates with HE4 levels, namely smoking. The mechanism remains unclear. We may hypothesize that the $\mathrm{HE} 4$ protein participates in the body's immunological response to smoking, because chronic inflammation of smokers' pulmonary tissues leads to an overexpression of the HE4 protein. The study of Bolstad et al. goes a step further and showed that the correlation is stronger in young patients [7]. However, our study population was too small to draw any further conclusions.

It should be mentioned that other authors have reported that HE4 protein levels also correlate with chronic heart failure, where the protein level is an independent prognostic factor that determines the risks of exacerbation 
TABLE 5: Generalized linear model. Age, BMI, creatinine, and smoking used for determination of different HE4 levels for the healthy and the benign tumor group.

\begin{tabular}{|c|c|c|c|c|c|c|}
\hline \multirow[t]{2}{*}{ Effect } & \multicolumn{6}{|c|}{$\begin{array}{c}\text { HE4-parameter estimates } \\
\text { Distribution-normal } \\
\text { Link function-identity }\end{array}$} \\
\hline & Estimate & Standard error & Wald stat. & Upper CL 95\% & Lower CL 95\% & $p$ \\
\hline Age & 0.408 & 0.160 & 6.442 & 0.093 & 0.723 & 0.011 \\
\hline BMI & 0.107 & 0.312 & 0.118 & -0.505 & 0.720 & 0.730 \\
\hline Creatinine & 28.557 & 11.455 & 6.214 & 6.104 & 51.010 & 0.012 \\
\hline Smoking & 4.809 & 1.610 & 8.919 & 1.653 & 7.966 & 0.002 \\
\hline
\end{tabular}

TABLE 6: The results of serum HE4 levels by pregnancy trimester.

\begin{tabular}{lccc}
\hline Trimester & $\begin{array}{c}\text { Median } \\
(\mathrm{pmol} / \mathrm{l})\end{array}$ & $\begin{array}{c}\text { Range (min-max) } \\
(\mathrm{pmol} / \mathrm{l})\end{array}$ & $\begin{array}{c}\text { Norm (pmol/l) } \\
(\mathrm{CL} 95 \%)\end{array}$ \\
\hline I & 40 & $28-69$ & $30-55$ \\
II & 43 & $15-80$ & $15-80$ \\
III & 53 & $30-117$ & $31-106$ \\
\hline
\end{tabular}

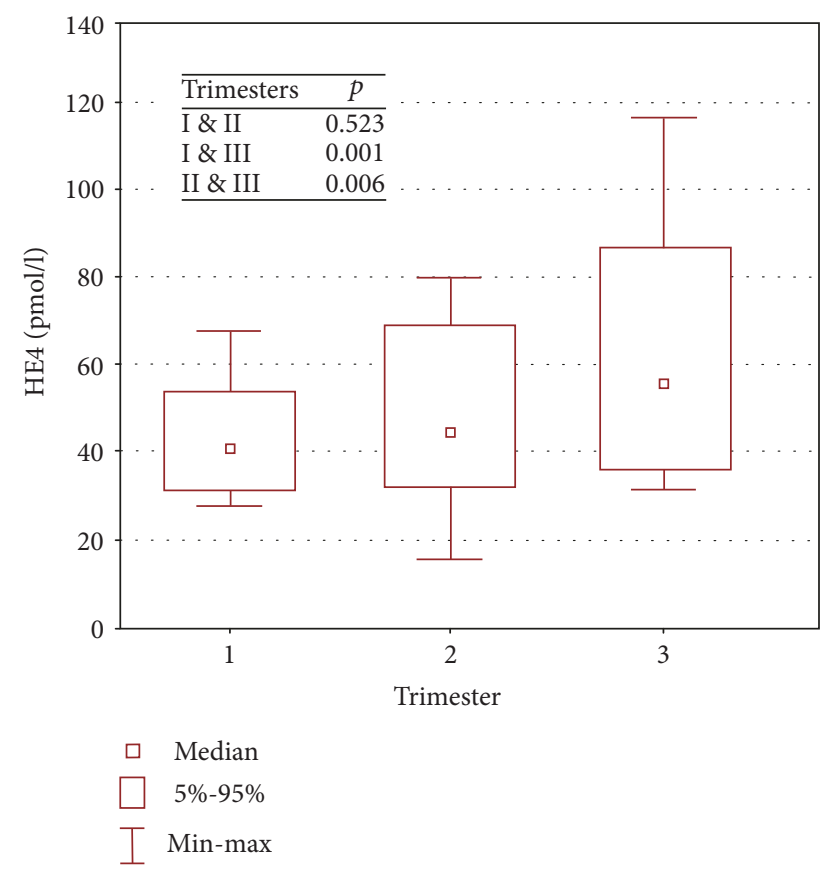

FIgURE 2: Serum HE4 levels by pregnancy trimester.

and death. In the same study, the authors reported a positive correlation between $\mathrm{HE} 4$ and other parameters, such as creatinine, NT-proBNP, galectin-3, and troponin T [12].

4.4. HE4 and Creatinine. Our study found no association between HE4 and creatinine. But when performing multivariate analyses, it turns out that this relationship exists if we take into account age and smoking. Our study clearly shows that age and smoking are factors that strongly affect the HE4 value. However, all our patients had creatinine levels within the reference range since those with kidney disease were excluded from the study. In turn, Bolstad has analyzed for any association with creatinine levels beyond the reference range and found a rising HE4 concentrations, which our clinical observations also confirm [7]. The reason is most probably that the impaired excretion of HE4 protein in the dysfunctional kidney leads to an accumulation of HE4 in the body. That the degree of kidney failure is related to rising HE4 concentrations is further supported by a study published in 2015, which revealed there were high HE4 concentrations in cases of kidney failure [13]. HE4 protein concentrations were high enough to invalidate differential diagnostic tests for ovarian tumors, and this fact needs to be considered when interpreting high HE4 scores. This fact also poses an important question about whether creatinine levels should be included in the diagnostic algorithm that utilizes HE4 concentrations. An answer is offered by the study of Kappelmayer et al. which showed that the logistic regression model involving CA125, HE4, and eGFR has no superior sensitivity in the detection of ovarian cancer [14]. The reason for this may be the fact that ovarian cancer diagnosis is usually undertaken in patients who have no kidney disease. In such cases, as showed by our study, normal creatinine values will have no effect on HE4 concentrations; hence, there will be no effect on ROMA and its diagnostic value.

4.5. HE4 and Pregnancy. In 2014, Hallamaa et al. analysed HE4 levels in a sample of 20 patients who underwent FSH treatment during in vitro fertilization [15]. He found that the HE4 levels were gonadotropin-independent. In turn, in 2015, Kanninen et al. found that among a vast array of markers, it was HE4 jointly with IL-13 that was the best predictive test for preterm labor. Compared with patients who underwent in vitro fertilization and had labor at term, those with relatively lower HE4 levels at approximately the 10th day after embryo transfer were at risk of preterm labor [16].

Our study has attempted to define the HE4 norm for healthy pregnant women for each trimester. The reference ranges we established may be of use in the detection of ovarian malignancy and in minimizing unnecessary surgical interventions that pose risks to both the mother and fetus. Although we observed no difference in the HE4 levels between the first and second trimesters, we did reveal statistically significant differences when each was compared with the third trimester (I and III, II and III). Moore et al., in a group of 67 patients, found no difference between trimesters I and II and trimesters I and III [8]. A study similar to Moore 
et al.'s from 2015 followed 26 pregnant patients through only their first and second trimesters and found no differences in HE4 concentrations [17]. This is in line with our findings, since the study excluded third trimester pregnancies during which we showed that HE4 rises significantly $[18,19]$. What lies behind this rise in third trimester concentration levels remains unknown. Further studies on HE4 function are needed to better understand the differences in HE4 concentrations during the various stages of pregnancy and in cases of benign, borderline, or malignant adnexal changes. The use of the HE4 marker is of great diagnostic value but requires further study involving a long observational period of healthy women that would eventually develop cancer of the ovary, salpinx, or peritoneum. We express the hope that the HE4 marker will be applicable in ovarian cancer screening, which is of utmost importance to enhance the early detection rate and to allow for more effective treatment.

\section{Conclusions}

(1) HE4 concentration is lowest during the first trimester, which is also the time when most tumors concurrent with pregnancy are detected. In such settings, it is crucial to bear in mind that the HE4 marker is elevated, together with the duration of the pregnancy irrespective of adnexal changes. Thus, physiological rising in HE4 levels must not be interpreted as an indication for surgical treatment

(2) By defining the normal range of the HE4 protein serum level, our study makes it possible to properly interpret measurements of the marker. This can result in earlier and more efficient diagnosis of ovarian malignancy

(3) We found no correlation between HE4 levels and BMI. However, we did find a positive correlation for HE4 levels and smoking and for HE4 levels and age

(4) We found no correlation between HE4 concentrations and creatinine levels within the reference range. But if we take into account age and smoking in multivariate analysis, there is a correlation

\section{Data Availability}

The data used to support the findings of this study are available from the corresponding author upon request.

\section{Ethical Approval}

The Local Bioethics Committee has approved the study, and informed consents were obtained from all patients participating in the study. The committee's reference number is $838 / 14$.

\section{Conflicts of Interest}

The authors declare that there is no conflict of interest.

\section{Authors' Contributions}

We confirm that all coauthors have been included and have contributed to the final manuscript and have approved it. EG have designed the study, collected the samples, analyzed the data, wrote the manuscript, and prepared the figures for this manuscript. TK collected the samples. DL and AT provided the biological material for analysis. WW performed the clinical statistical analysis. ENM provided the biological material for analysis and critically reviewed the manuscript.

\section{Acknowledgments}

We thank ROCHE Diagnostics Polska for providing the reagents for measurement HE4 protein concentration by ECLIA. This work was supported by the Poznan University of Medical Sciences institutional grant no. 50201111014000257.

\section{References}

[1] R. G. Moore, M. C. Miller, M. M. Steinhoff et al., "Serum HE4 levels are less frequently elevated than CA125 in women with benign gynecologic disorders," American Journal of Obstetrics and Gynecology, vol. 206, no. 4, pp. 351.e1351.e8, 2012.

[2] R. G. Moore, M. C. Miller, P. Disilvestro et al., "Evaluation of the diagnostic accuracy of the risk of ovarian malignancy algorithm in women with a pelvic mass," Obstetrics and Gynecology, vol. 118, 2, Part 1, pp. 280-288, 2011.

[3] M. Kamei, S. Yamashita, K. Tokuishi et al., "HE4 expression can be associated with lymph node metastases and diseasefree survival in breast cancer," Anticancer Research, vol. 30, no. 11, pp. 4779-4783, 2010.

[4] R. L. O'Neal, K. T. Nam, B. J. LaFleur et al., "Human epididymis protein 4 is up-regulated in gastric and pancreatic adenocarcinomas," Human Pathology, vol. 44, no. 5, pp. 734-742, 2013.

[5] L. Bingle, S. S. Cross, A. S. High et al., "WFDC2 (HE4): a potential role in the innate immunity of the oral cavity and respiratory tract and the development of adenocarcinomas of the lung," Respiratory Research, vol. 7, no. 1, p. $61,2006$.

[6] B. J. Nagy, Z. T. Krasznai, H. Balla et al., "Elevated human epididymis protein 4 concentrations in chronic kidney disease," Annals of Clinical Biochemistry, vol. 49, no. 4, pp. 377-380, 2012.

[7] N. Bolstad, M. Øijordsbakken, K. Nustad, and J. Bjerner, "Human epididymis protein 4 reference limits and natural variation in a Nordic reference population," Tumour Biology, vol. 33, no. 1, pp. 141-148, 2012.

[8] R. G. Moore, M. C. Miller, E. E. Eklund, K. H. Lu, R. C. Bast Jr., and G. Lambert-Messerlian, "Serum levels of the ovarian cancer biomarker HE4 are decreased in pregnancy and increase with age," American Journal of Obstetrics and Gynecology, vol. 206, no. 4, pp. 349.e1-349.e7, 2012.

[9] Y. Tian, C. Wang, L. Cheng et al., "Determination of reference intervals of serum levels of human epididymis protein 4 (HE4) in Chinese women," Journal of Ovarian Research, vol. 8, no. 1, p. 72, 2015. 
[10] R. Molina, J. M. Escudero, J. M. Augé et al., "HE4 a novel tumour marker for ovarian cancer: comparison with CA 125 and ROMA algorithm in patients with gynaecological diseases," Tumour Biology, vol. 32, no. 6, pp. 1087-1095, 2011.

[11] M. A. Karlsen, E. V. S. Høgdall, I. J. Christensen et al., “A novel diagnostic index combining HE4, CA125 and age may improve triage of women with suspected ovarian cancer An international multicenter study in women with an ovarian mass," Gynecologic Oncology, vol. 138, no. 3, pp. 640-646, 2015.

[12] A. Piek, W. C. Meijers, N. F. Schroten, R. T. Gansevoort, R. A. de Boer, and H. H. W. Silljé, "HE4 serum levels are associated with heart failure severity in patients with chronic heart failure," Journal of Cardiac Failure, vol. 23, no. 1, pp. 12-19, 2017.

[13] Y. W. Lv, L. Yang, M. Zhang et al., "Increased human epididymis protein 4 in benign gynecological diseases complicated with chronic renal insufficiency patients," Genetics and Molecular Research, vol. 14, no. 1, pp. 2156-2161, 2015.

[14] J. Kappelmayer, P. Antal-Szalmas, and B. Nagy Jr., "Human epididymis protein 4 (HE4) in laboratory medicine and an algorithm in renal disorders," Clinica Chimica Acta, vol. 438, pp. 35-42, 2015.

[15] M. Hallamaa, K. Huhtinen, P. Suvitie, and A. Perheentupa, "Serum concentrations of HE4 change little during in vitro fertilization," Acta Obstetricia et Gynecologica Scandinavica, vol. 93, no. 7, pp. 640-646, 2014.

[16] T. T. Kanninen, G. Sisti, I. Ramer, D. Goldschlag, S. S. Witkin, and S. D. Spandorfer, "Predictive biomarkers of preterm delivery in women with ongoing IVF pregnancies," Journal of Reproductive Immunology, vol. 112, pp. 58-62, 2015.

[17] F. Gucer, G. Kiran, E. Canaz et al., "Serum human epididymis protein 4 can be a useful tumor marker in the differential diagnosis of adnexal masses during pregnancy: a pilot study," European Journal of Gynaecological Oncology, vol. 36, no. 4, pp. 406-409, 2015.

[18] J. Lu, Z. Zheng, Q. Zhang et al., "Measurement of HE4 and CA125 and establishment of reference intervals for the ROMA index in the sera of pregnant women," Journal of Clinical Laboratory Analysis, vol. 32, no. 5, 2018.

[19] Z. Wang, F. Zhou, X. Xiao, and C. Ying, "Serum levels of human epididymis protein 4 are more stable than cancer antigen 125 in early and mid-term pregnancy," The Journal of Obstetrics and Gynaecology Research, vol. 44, no. 11, pp. 2053-2058, 2018. 


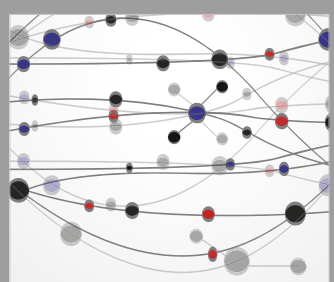

The Scientific World Journal
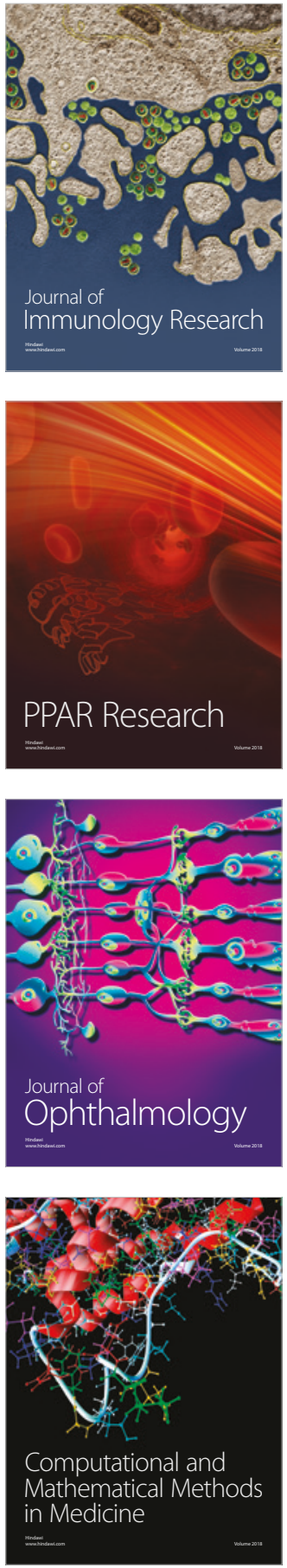

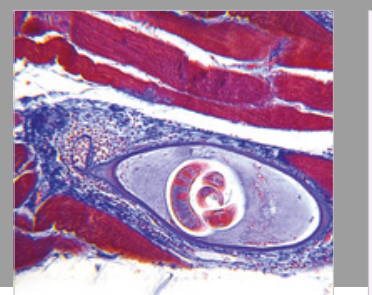

Gastroenterology Research and Practice

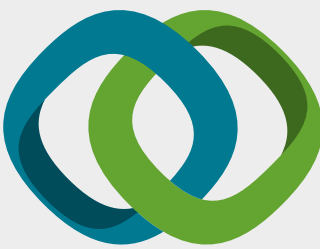

\section{Hindawi}

Submit your manuscripts at

www.hindawi.com
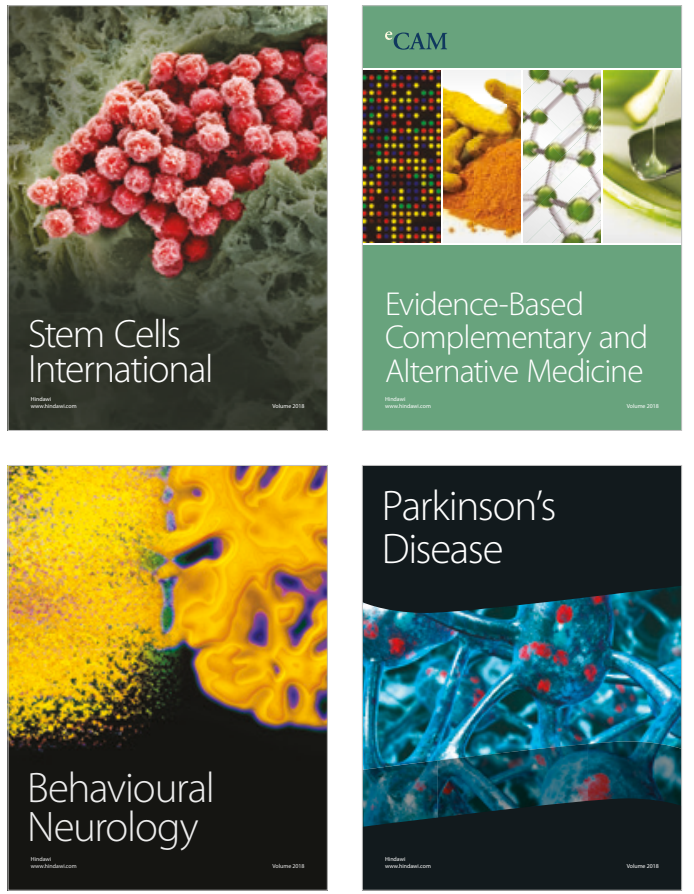

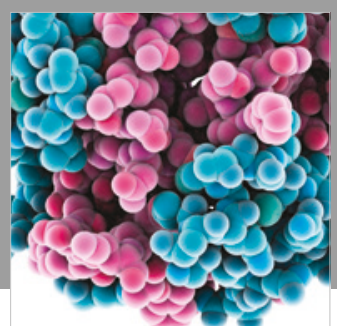

ournal of

Diabetes Research

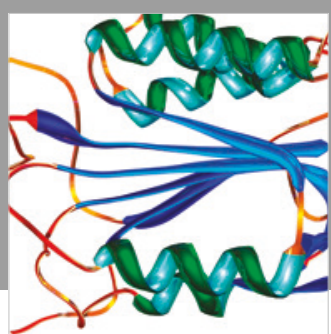

Disease Markers
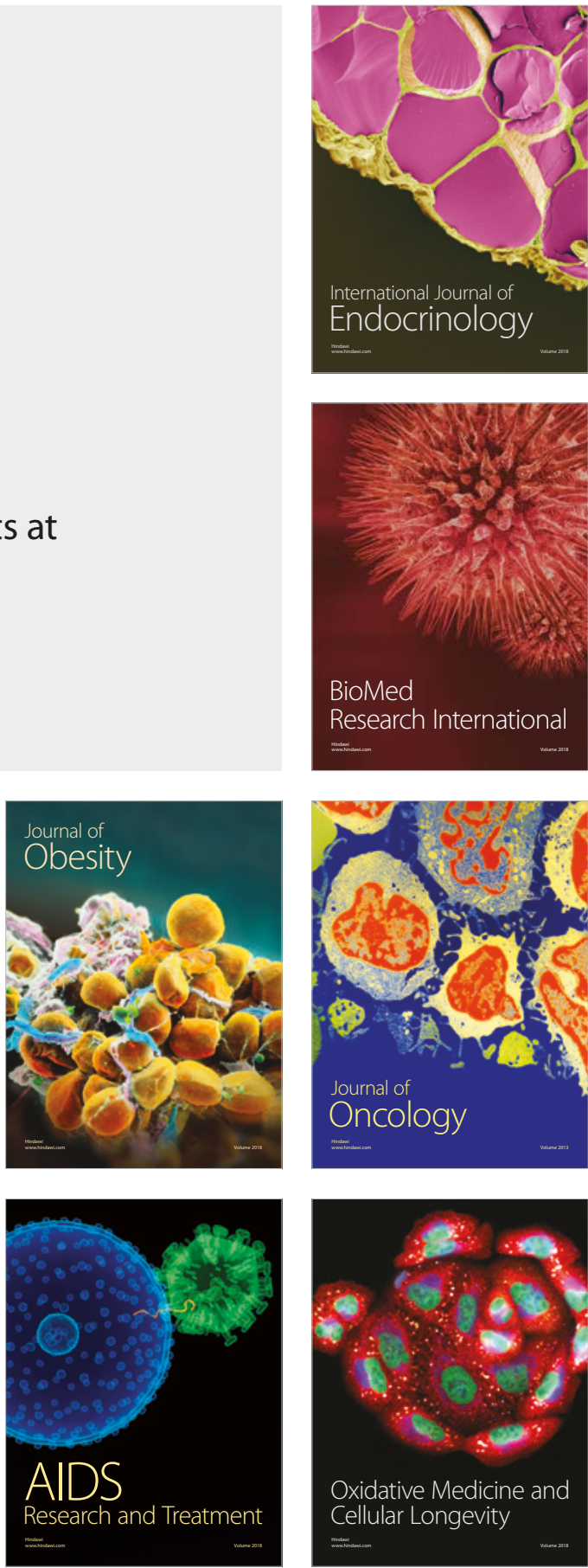